\title{
Late Onset Alzheimer Dementia in Patients with Genotype E3/E4: A Case Report
}

\author{
Anak Agung Ayu Putri Laksmidewi*, Chiquita Putri Vania Rau \\ Department of Neurology, Faculty of Medicine, Udayana University, Sanglah General Hospital, Bali, Indonesia
}

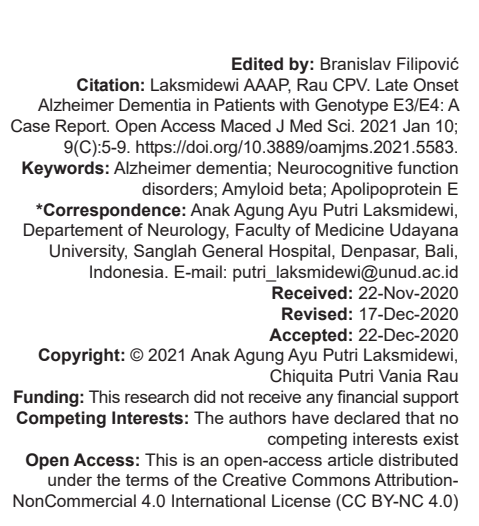

Abstract

BACKGROUND: Dementia is one of the leading causes of disability and dependence in elderly worldwide. Epidemiological statistics indicate that data show that at about $60-80 \%$, Alzheimer's is the most common type of dementia. Alzheimer's is also the third-most prominent cause of death in elderly.

CASE REPORT: A 72-years-old male patient, complained by the family often forgets about things that have just been done for 3 years ago. According to the family, patient also often discussing the same things repeatedly. Patients tend not to have the initiative to start his daily activities. The family admitted that patient also became often angry and felt suspicious for the last 2 years. From the mini mental state examination showed disturbances in time orientation and recall; from Montreal Cognitive Assessment Ina found disturbances in visuospatial, fluency, abstraction, delayed memory, and time orientation; accompanied by activities of daily living (ADL) and instrumental ADL disorders. Patient also performed a molecular examination of the apolipoprotein E (APOE) genotype and the genotype E3/E4 was detected.

CONCLUSION: The function of the APOE gene, in particular APOE4, is the most emphasized genetic relationship in late onset Alzheimer's disease. It is proposed that blocking the action of APOE4 can delay or stop Alzheimer's disease progression.

\section{Background}

Dementia is a condition that reduces brain ability compared to before which is serious enough to conflict with their social and career activities, usually there are also behavioral changes that are not caused by delirium or major psychiatric disorders [1]. Two commonly known types of dementia, Alzheimer's disease dementia and vascular dementia, are available. These two dementias can be distinguished by the presence or absence evidence of vascular abnormalities as a suspected factor [2].

In older patients globally, one of the main causes of incapacity and dependence is dementia. This can have an effect not only for the patient but also for people around him (caregiver and family). Lack of understanding of dementia in society makes diagnosis and treatment of dementia patients difficult [3].

One of the prominent health concerns in society is dementia. Cases of dementia are present in about 47 million individuals globally, and it is estimated that cases will still increase to 131 million in 2050 [4]. Epidemiological statistics suggest that in between $60 \%$ and $80 \%$ of patients, Alzheimer's is the most prevalent type of dementia [5]. Alzheimer's following coronary and cerebrovascular disease (CVD) and malignancy is the third most frequent cause of death in the elderly [6].
Alzheimer is the sixth leading cause of death in the United States, spending around 172 billion dollars a year in healthcare [7]. In Indonesia, the estimated number of Alzheimer's patients reached 1 million in 2013. Based on data from the Indonesian Ministry of Health, life expectancy in Indonesia has increased from 68.6 years (2004) to 72 years (2015). This increase in life expectancy will increase the percentage of the elderly population. Therefore, it is estimated that the number of Alzheimer's patient will increase every year [8].

\section{Case Report}

A 72-years-old male patient, right handed, complained by his family that he often forgot about something for 3 years ago. Patients are initially said to be forgetful about new things being done. Complaints about forgetting are felt to get worse over time, until the patient forgets basic things such as the date or year. However, according to the family, the patient is still able to recognize and remember the names of his family members. Patients are also admitted to often discussing the same things over and over again, especially about his previous work at the hotel. Patients are said to be able to carry out his daily activities independently but 
tend not to have the initiative to start his activities. Family said the patient had to be repeatedly asked to take a bath and eat before he would do it.

The patient was also said to be often angry and suspicious for the past 2 years. Several times, he was suspicious of some people who were considered intending to steal his belongings. The patient is said to have become aggressive with sometimes a slightly high voice, but he did not end up hurting others or himself. Due to this complaint, the family had brought the patient to a psychiatric doctor. At that time he was given three kinds of drugs, namely, Quetiapine (which is an anti-psychotic), Memantine Hydrochloride, and Escitalopram (which belongs to the SSRI class). The family acknowledged that since the patient took the drug, his aggressiveness decreased and the he became more quiet at home and lazy to do activities. The complaint was not accompanied by partial body weakness, slurred voice, tingling, or slanting lips.

This is the $1^{\text {st }}$ time he has experienced a similar complaint. The patient has no previous history of other diseases. From the family history, it was found that his mother had experienced similar complaints, which is memory problems in the form of often forgetting something until she finally died. The patient is a bachelor's degree graduate and previously worked as an employee in a hotel.

Physical examination revealed good general condition, vital signs within normal limits with a blood pressure of $120 / 80 \mathrm{mmHg}$, and no focal neurological deficit. The results of the neurocognitive examination are summarized in Table 1.

Table 1: Results of neurocognitive examination

\begin{tabular}{ll}
\hline Behavioral observation & $\begin{array}{l}\text { No history of behavior change, denial/neglect, and } \\
\text { neurological deficits }\end{array}$ \\
Awareness & Compos mentis \\
Attention & Attention and observation $(+)$ \\
Digit span & Normal \\
Vigilance & Normal \\
Language component & Fluent spontaneous speaking, repetition, naming, reading, \\
& and writing normally \\
Memory & Disruption in immediate memory and new learning abilities \\
Visuospatial & Normal \\
Executive function & Disturbed \\
\hline
\end{tabular}

From the screening test, it was obtained mini mental state examination (MMSE) score of 22 (disruption in time orientation and recall); Montreal Cognitive Assessment (MoCA) Ina 18 (impaired visuospatial, fluency, abstraction, delayed memory, and time orientation); clock drawing test (CDT) 2; activities of daily living (ADL) score 2; and instrumental ADL (IADL) score 11. The CDR test was categorized as severe dementia, with the Hamilton Depression Rating Scale of 6 (no depression) or had recovered and the Ina AD-8 questionnaire score was 8 .

From investigations, laboratory tests show an impression within normal limits. Contrast-enhanced magnetic resonance imaging examination of the brain revealed age-related cerebral atrophy as shown in Figure 1. From the Apolipoprotein E (APOE) genotype molecular examination, genotype E3/E4 was detected with the impression that an increased risk of Alzheimer's disease in symptomatic individuals.
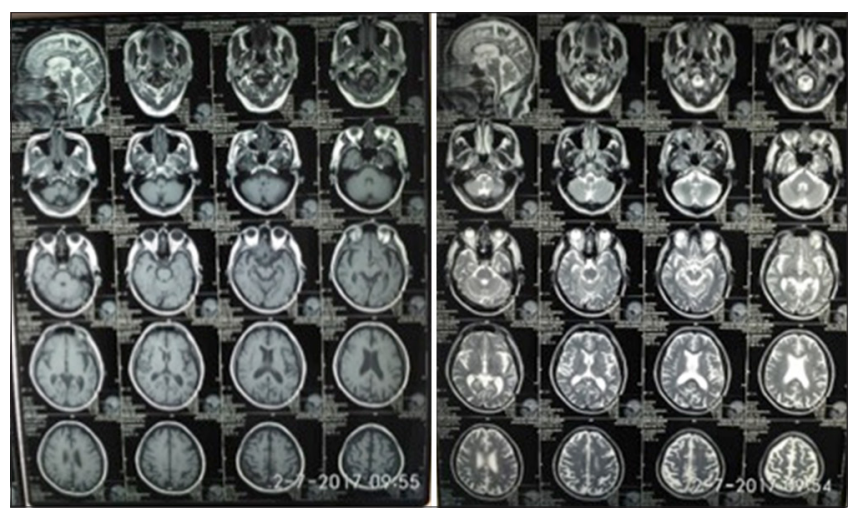

Figure 1: Contrast-enhanced magnetic resonance imaging

The patient was later diagnosed with lateonset Alzheimer's dementia (DA). The pharmacological therapies given are acetylsalicylic acid (NSAID) and memantine hydrochloride. Meanwhile, the nonpharmacological therapy that is given is cognitive stimulation at the Behavior Clinic of Sanglah Hospital every 2 times a week. Cognitive stimulation is given in the form of attention, visuomotor, reaction, and visual choice; memory, visuomotor, and reactions; memory; memory, attention, and executive functions; memory and visuospatial; and association and memory strategies. The patient had done the exercise for 5 times and was evaluated on a screening test every time the patient came.

A comparison evaluation was carried out between the results of the screening when the patient first arrived and the last patient arrived (with an interval of 3 weeks). The results of the comparison show that the patient got some increase in value. Based on the results of the initial MMSE, the score was 22 (disturbance in time orientation and recall), while the last time was control with a score of 24 (disturbance in time orientation and recall); initial MoCA Ina score was 18 (disruption in visuospatial impairment, fluency, abstraction, delayed memory, and time orientation) and last control time with a score of 23 (delayed memory and orientation impairment). At the initial CDT examination, it got a value of 2, while at the last control, it was 4 (normal). Meanwhile, the ADL and IADL scores did not show any changes.

\section{Discussion}

Dementia is a syndrome, which is usually chronic or progressive, and there is decreased cognitive function (i.e., the ability to think). Dementia affects memory, thought process, orientation, comprehension, computation, learning ability, language, and assessment. Cognitive disorders are usually accompanied and 
sometimes preceded by an inability to control emotions, social behavior, or motivation [3]. Dementia is a multimanifest psychiatric condition that seeks to recognize the cause of dementia and can direct its treatment. Dementia caused by Alzheimer's is easier to distinguish from other causes in the early stages of the diseases. This is because dementia at an advanced stage almost always displays the same clinical manifestations even though it is caused by different etiologies [9].

The manifestations of dementia can be separated into two categories in general, namely, cognitive and non-cognitive conditions. Cognition complaints consist of memory problems, especially the ability to learn new material which is often the earliest complaint from patients. Old memory can be impaired in late stage dementia. Patients usually experience disorientation around the house or in relatively new environments. Non-cognition complaints include neuropsychiatric complaints or behavioral neuropsychological symptoms of dementia (BPSD). Behavioral components include agitation, aggressive action, and non-aggressive actions such as sundowning syndrome, wandering, and other symptoms. Sleep disorders, depression, and other psychological symptoms such as hallucinations and paranoia are the most prominent concerns. Motor disorders can also be found in the form of difficulty walking, slurred speech, myoclonic seizures, and others [1].

Its clinical characteristics include progressive decline in episodic memory and other cortical functions. Motor disturbances are not found except in the late stages of the disease. Behavioral disturbances and dependence in ADL following episodic memory disorders support the diagnosis of this disease [1]. Alzheimer's disease, which is Early-Onset Alzheimer's Disease (EOAD) and Late-Onset Alzheimer's Disease (LOAD), is subdivided into 2 age-based categories. EOAD is a less prevalent form of Alzheimer's disease, with an incidence of only $5 \%$ of all Alzheimer's cases, also known as familial Alzheimer's disease, occurring at an earlier age (<65 years) [10]. Meanwhile, LOAD is something that is more complex and occurs relatively slowly (>65 years), is found in $95 \%$ of cases, and is also known as sporadic Alzheimer's disease [11].

The pathological process of dementia occurs several years before the clinical picture becomes clear. Mild cognitive impairment $(\mathrm{MCl})$ is defined as the transition period of $\mathrm{MCl}$ between the natural ageing process and the development of DA. In people with diagnosed dementia, a thorough clinical review covering all three areas of thought, behavior, and function is needed to allow an early diagnosis, assess symptoms, and determine the cause of dementia. Combining the family interview test with a cognition test will improve the prediction accuracy of dementia compared to the individual test. Some of the commonly used and recommended instruments for screening are the MoCA, AD8, MMSE, and CDT. Functional conditions can be measured based on ADL, both basic ADL and IADL. The capacity to live in the society individually would be represented by both [1].

Behavioral changes are found in the majority of dementia patients, this will be more often seen as dementia progresses. Neuropsychiatric symptoms, or commonly termed BPSD, such as agitation, anxiety, paranoia, depression, sleep disorders, and hallucinations are found in $90 \%$ patients with Alzheimer's. Aggression and agitation are the most common complaints, found in $30-50 \%$ of dementia patients. In cases accompanied by BPSD, specific neuropsychological tests can be added [1].

Alzheimer's disease is a multifactorial neurodegenerative disease, which contain a mixture of protein aggregates, chronic nerve inflammation, and loss of neuron cells. Alzheimer's disease is pathologically characterized by the involvement of amyloid beta $(A \beta)$ plaques and neurofibrillary tangles (NFTs) which can cause neurodegeneration and eventually lead to neuronal cell death. Several studies show that there Alzheimer's can be caused by two classes of risk factors, which are modifiable risk factors and non-modifiable risk factors. Non-modifiable variables are intended as risks that increase the likelihood of developing Alzheimer's disease and cannot be modified to date. These are the factors by which a person is born with the condition including aging, genetic variants, family history of disease, race, and sex. While the factors that can be modified include the level of education, lifestyle, and exposure that may be faced, because all of them can affect a person's health [12].

An increased risk of developing EOAD and LOAD has been linked with genetic variance. Genes that play role in EOAD development were autosomal dominant genes, which are APP, PSEN1, and PSEN2 [13]. While the role of genetics in Late Onset Alzheimer's Disease (LOAD) itself is still not widely explained, only a few studies have explained this. Some of these studies stated that the role of the APOE gene on chromosome 19 is the most prominent [14]. There are three main ApoE alleles in humans, which are $\varepsilon 2, \varepsilon 3$, and $\varepsilon 4$. ApoE2 is associated with a decreased risk of Alzheimer's disease (has a $40 \%$ lower chance of developing Alzheimer's disease), ApoE3 is an allele found in a large proportion of the population, while the increased risk is associated with APOE4 [15]. It is said that the existence of ApoE2 delays the incidence of hereditary Alzheimer's disease/EOAD [16]. In some literature, it is said that APOE2 has protective properties against Alzheimer's, associated with an increase in plasma cholesterol and triglyceride levels and a syndrome called dysbetalipoproteinemia, which also correlated with coronary artery disease [17]. Meanwhile, an increased occurrence of atherosclerosis and an increased risk of Alzheimer's are linked with ApoE4 by $8-12 x$. There are studies which also say that the onset of dementia, working memory, and a higher $A \beta$ load would worsen in Alzheimer's patients with the ApoE4 isoform [18]. 
APOE is a protein containing lipids that are greatly active in the metabolism of cholesterol. In its role with Alzheimer's, APOE itself has a role including its relationship with $A \beta$ metabolism, tau protein phosphorylation, neuroinflammation, and others [19].

\section{A $\beta$ metabolism}

In Alzheimer' patients, carriers of ApoE4, the deposition of $A \beta$ was higher than that of non-carriers. ApoE concentrations in CSF and plasma in ApoE4 carriers are usually lower; this indicates that lower levels of ApoE will contribute to the brain's accumulation of $A \beta$. This is in line with multiple experiments demonstrating that in several regions of the brain, ApoE levels are adversely associated with $A \beta$ levels. It was observed that ApoE4 influences multiple primary stages in the amyloid cascade, including $A \beta$ aggregation and deposition, in an animal model analysis using replacement mice.

\section{Tau protein phosphorylation}

A major component of NFTs is tau hyperphosphorylation. To explain the impact of ApoE4 on tau hyperphosphorylation, two complementary mechanisms have been suggested, namely:

\section{Direct mechanism}

Given the fact whether ApoE3 has been shown to be more efficient than ApoE4 in targeting nonphosphorylated tau, high ApoE3 levels would prevent tau from accumulating.

\section{Indirect mechanism}

Due to its peculiar form, ApoE4 in neurons is thought to be able to exit the secretory pathway and will specifically interact with tau in the cytoplasm so that it can cause hyperphosphorylation.

\section{Neuroinflammation}

In a study using mice, after inflammatory stimulation, the ApoE4-carrying mice had a prolonged and increased neuroinflammatory response. The impact of ApoE4 on the microglial activation mechanism and also its interaction with elevated levels of proinflammatory cytokines can cause this inflammation.

Several experiments have shown that this inflammatory activity of ApoE4 can be linked with miRNA 146a, which is located predominantly in miRNA in the brain. A possible influencing mechanism is that increased levels of miRNA146a levels can contribute to inadequate inflammation regulation of negative feedback which will result in a chronic inflammation.

\section{Conclusion}

Alzheimer's is a neurodegenerative, multifactorial condition that includes a mixture of protein aggregates, chronic nerve inflammation, and loss of neuronal cells. Alzheimer's following coronary and CVD and malignancy is the third most frequent cause of death in the elderly. The function of the APOE gene, ApoE4, is the most emphasized genetic relationship in LOAD. In its role with Alzheimer's, APOE itself has several main roles, including its relationship with $A \beta$ metabolism, tau protein phosphorylation, and neuroinflammation. Taking into account the assumption that ApoE4 is harmful to the brain, blocking the operation may be proposed to slow or avoid the development of Alzheimer's disease. Blocking the effects of ApoE4 in particular can be done by genomic, biochemical, and immunological approaches. It is estimated that this approach will help $40-60 \%$ of PA patients who carry ApoE4.

\section{References}

1. Ong PA, Muis A, Rambe S, Widjojo FS, Laksmidewi AA Panduan klinik: Diagnosis dan Penatalaksanaan Demensia. Jakarta: Perhimpunan Dokter Spesialis Saraf Indonesia; 2015.

2. Stewart R. Cardiovascular factors in Alzheimer's disease. J Neurol Neurosurg Psychiatry. 1998;65(2):143-7.

PMid:20413875

3. World Health Organization. Dementia. Geneva: World Health Organization; 2019. Available from: https://www.who.int/newsroom/fact-sheets/detail/dementia. [Last accessed on 2020 Oct 27].

4. Alzheimer's Disease International. World Alzheimer Report 2015: The Global Impact of Dementia: An Analysis of Prevalence, Incidence, Cost and Trends. Alzheimer's Disease International; 2015. Available from: https://www.alz.co. uk/ research/WorldAlzheimerReport2015.pdf. [Last accessed on 2020 Nov 01].

5. Mielke MM, Vemuri P, Rocca WA. Clinical epidemiology of Alzheimer's disease: Assessing sex and gender differences. Clin Epidemiol. 2014;6:37-48. https://doi.org/10.2147/clep. s37929

PMid:24470773

6. Du X, Wang X, Geng M. Alzheimer's disease hypothesis and related therapies. Translational Neurodegeneration 2018;7:1-7. PMid:29423193

7. Lakhan SE, Chawla J. Alzheimer Disease; 2019. Available from: https://www.emedicine.medscape.com/article/1134817overview. [Last accessed on 2020 Nov 13].

8. Kemenkes RI. Menkes: Lansia Yang Sehat, Lansia Yang Jauh Dari Dementia; 2017. Available from: http://www.depkes.go.id/ article/print/16031000003/menkes-lansia-yang-sehat-lansiayang-jauh-dari-dementia.html. https://doi.org/10.32528/emp. v2i0.1387. [Last accessed on 2020 Nov 18].

9. Corriveau RA, Koroshetz WJ, Gladman JT, Jeon S, Babcock D, Bennett DA, et al. Alzheimer's disease-related dementias summit 2016: National research priorities. Neurology 2017;89(23):2381-91. 
PMid:29117955

10. Zhu XC, Tan L, Wang HF, Jiang T, Cao L, Wang C, et al. Rate of early onset Alzheimer's disease: A systematic review and metaanalysis. Ann Transl Med. 2015;3(3):38.

PMid:25815299

11. Rosenthal SL, Kamboh MI. Late-onset Alzheimer's disease genes and the potentially implicated pathways. Curr Gen Med Rep. 2014;2(2):85-101. https://doi.org/10.1007/ s40142-014-0034-x

PMid:24829845

12. Eid A, Mhatre I, Richardson JR. Gene-environment interactions in Alzheimer's disease: A potential path to precision medicine. Pharmacol Ther. 2019;199:173-87. https://doi.org/10.1016/j. pharmthera.2019.03.005

PMid:30877021

13. Dai MH, Zheng $\mathrm{H}$, Zeng LD, Zhang $\mathrm{Y}$. The genes associated with early-onset Alzheimer's disease. Oncotarget. 2018;9(19):1513243. https://doi.org/10.18632/oncotarget.23738 PMid:29599933

14. Apostolova LG, Risacher SL, Duran T. Associations of the top 20 Alzheimer disease risk variants with brain amyloidosis. JAMA Neurol. 2018;75(3):328-41. https://doi.org/10.1001/ jamaneurol.2017.4198

\section{PMid:29340569}

15. Mahley RW. Central nervous system lipoproteins highlights Arterioscler Thromb Vasc Biol. 2016;36(7):1305-15.

PMid:27174096

16. Vélez JI, Lopera F, Sepulveda-Falla D, Patel HR, Johar AS, Chuah A. APOE*E2 allele delays age of onset in PSEN1 E280A Alzheimer's disease. Mol Psychiatry. 2016;21(7):916-24. https:// doi.org/10.1038/mp.2015.177

PMid:26619808

17. Marais AD, Solomon GA, Blom DJ. Dysbetalipoproteinaemia: A mixed hyperlipidaemia of remnant lipoproteins due to mutations in apolipoprotein E. Crit Rev Clin Lab Sci 2014;51(1):46-62. https://doi.org/10.3109/10408363.2013.870526 PMid:24405372

18. Yamazaki Y, Zhao N, Caulfield TR, Liu CC, Bu G. Apolipoprotein E and Alzheimer disease: Pathobiology and targeting strategies. Nat Rev Neurol. 2019;15(9):501-18. https://doi.org/10.1038/ s41582-019-0228-7

PMid:31367008

19. Safieh M, Korczyn AD, Michaelson DM. ApoE4: An emerging therapeutic target for Alzheimer's disease. BMC Med. 2019;17(1):64. https://doi.org/10.1186/s12916-019-1299-4 PMid:30890171 